\title{
PLK1 Inhibitor TAK-960
}

National Cancer Institute

\section{Source}

National Cancer Institute. PLK1 Inhibitor TAK-960. NCI Thesaurus. Code C92587.

An orally available, Polo-like kinase 1 (PLK1) inhibitor with potential antineoplastic activity. Polo-like kinase 1 inhibitor TAK-960 selectively inhibits PLK1, inducing selective G2/M cellcycle arrest followed by apoptosis in a variety of tumor cells while causing reversible cellcycle arrest at the G1 and G2 stages without apoptosis in normal cells. PLK1 inhibition may result in the inhibition of proliferation in PLK1-overexpressed tumor cells. PLK1, named after the polo gene of Drosophila melanogaster, is a serine/threonine kinase crucial in the regulation of mitosis. 